OPEN ACCESS

Edited by:

Maria Jose Torres,

University of Málaga, Spain

Reviewed by:

Ricardo Madrigal-Burgaleta,

Barts Health NHS Trust,

United Kingdom

Victoria Cardona,

Vall d'Hebron University Hospital,

Spain

*Correspondence:

Sevim Bavbek

bavbek@medicine.ankara.edu.tr orcid.org/0000-0002-7884-0830

Specialty section:

This article was submitted to

Translational Pharmacology,

a section of the journal

Frontiers in Pharmacology

Specialty section:Invalid type

Received: 15 June 2020

Accepted: 20 August 2020

Published: 08 September 2020

Citation:

Fouda GE and Bavbek S (2020)

Rituximab Hypersensitivity: From Clinical Presentation to Management.

Front. Pharmacol. 11:572863. doi: 10.3389/fphar.2020.572863

\section{Rituximab Hypersensitivity: From Clinical Presentation to Management}

\author{
Ghada E. Fouda ${ }^{1}$ and Sevim Bavbek ${ }^{2 *}$ \\ ${ }^{1}$ Allergy and Immunology Center, Al-Azhar University, Cairo, Egypt, ${ }^{2}$ Division of Immunology and Allergy, Department of \\ Chest Diseases, Ankara University School of Medicine, Ankara, Turkey
}

Rituximab is a chimeric monoclonal antibody (mAb) against CD20 molecule which is expressed on human B cells. It has been used for the treatment of various lymphoid malignancies, lymphoproliferative diseases, and rheumatologic disorders. Rituximab is generally well tolerated. However, increased use of rituximab has been associated with hypersensitivity reactions (HSRs), which can be classified as infusion-related, cytokinerelease, type I (IgE/non-IgE), mixed, type III, and type IV reactions. Immediate infusionrelated reactions to rituximab are quite common and decrease in frequency with subsequent infusions. However, in about 10\% of patients, severe infusion-related reactions develop, which prevent its use. Some of the immediate infusion reactions are due to a cytokine-release but some reactions raise concerns for type I (lgE/non-lgE) hypersensitivity. Recent studies have shown the presence of serum anti-rituximab antibodies, either represented by the IgG or IgE isotype. In some cases, clinical manifestations of IgE-mediated reactions and cytokine-release reactions partially overlap, which is called a mixed reaction. Classified as Type III reaction, rituximabinduced serum sickness reactions have been reported in patients with autoimmune diseases and hematological malignancies. The classic serum sickness triad (fever, rash, and arthralgia) has been observed in patients mainly with an underlying rheumatologic condition. Severe delayed type IV hypersensitivity reactions including non-severe maculopapular rash to severe reactions such as Stevens-Johnson syndrome and toxic epidermal necrolysis have been rarely reported following rituximab injection. Comprehensive reviews focused on rituximab-induced HSRs are scarce. We aimed to review clinical presentations, underlying mechanisms of rituximab hypersensitivity, as well as management including rapid drug desensitization.

Keywords: biologic agents, rituximab, hypersensitivity, desensitization, drug allergy, serum sickness, monoclonal antibody, infusion reaction

\section{INTRODUCTION}

Monoclonal antibodies (mAbs) have become mandatory for neoplastic targeted therapies as well as chronic inflammatory and autoimmune diseases (Beck et al., 2010; Li et al., 2013; Patel and Khan, 2017; Picard and Galvão, 2017; Özyiğit et al., 2020). Rituximab is a chimeric IgG mAb directed against CD20 antigen that is expressed on normal and malignant B cells (Plosker and Figgitt, 2003). 
It was initially approved as an anti-neoplastic agent (Vikse et al., 2019). Later on, it became a bright treatment opportunity instead of the conventional treatment for chronic granulomatosis and inflammatory diseases (Wong and Long, 2017).

Rituximab treatment results in two main categories of adverse reactions, including immunodeficiency and hypersensitivity reactions (HSRs). The drug is considered to be of good and accepted tolerability, (Vidal et al., 2011; Makatsori et al., 2014); however, increased use of rituximab has been associated with HSRs (Brennan et al., 2009; Patel and Khan, 2017; Picard and Galvão, 2017; Isabwe et al., 2018). Comprehensive reviews focused on rituximab-induced HSRs are scarce. This article aimed to review and describe clinical presentations, underlying mechanisms of rituximab hypersensitivity as well as management including rapid drug desensitization (RDD).

\section{HYPERSENSITIVITY REACTIONS TO RITUXIMAB}

\section{Classification and Prevalence}

Adverse drug reactions are classified into two major types: type A reactions are common and may occur in any individual. Type $\mathrm{B}$ reaction, also called "Drug Hypersensitivity", is uncommon, unpredictable, and occurs only in susceptible individuals. Drug Hypersensitivity occurs via immune (allergic) or non-immune mechanisms. Allergic drug reactions can manifest with many different clinical presentations, and to better explain these variations in clinical presentations, traditional Gell and Coombs classification is used (Pichler, 2006).

Like other pharmaceutical agents, biological agents can cause adverse drug reactions. Because of the inherent differences between biologicals and pharmaceutical drugs, adverse reactions to biologicals cannot be classified according to the traditional classification. Therefore, alternative classification schemes have been suggested. One proposal by Pichler is based on the immunological activity of biologicals and to distinguish it from the classification of adverse drug reactions, the Greek alphabets, alfa, beta, gamma, delta, and epsilon have been used. This classification includes five groups: (Type $\alpha$ ) high cytokine levels, (Type $\beta$ ) hypersensitivity reactions, IgE, IgG, and T cell mediate reactions, (Type $\delta$ ) immune imbalance syndrome, (Type $\gamma$ ) cross-reactivity with native proteins, and (Type $\varepsilon$ ) nonimmunologic adverse effects (Pichler, 2006; Patel and Khan, 2017; Wong and Long, 2017). Alfa reactions are associated with high cytokine levels, and in most cases, high cytokine levels occur due to endogenous cell activation, that is called a cytokine release reaction. Beta-type reactions are HSRs and are further defined as immediate and delayed and occur with IgE, IgG, and complement or T cell involvement. (Pichler, 2006; Corominas et al., 2014; Picard and Galvão, 2017).

However, recently a new classification was proposed considering phenotypes, endotypes, and biomarkers indicating underlying endotype. Phenotype and endotypes were based on the clinical presentation, the cells and mediators involved in the reaction respectively. The classification proposes four patterns of phenotypes: type I reactions (IgE/non-IgE), cytokine-release reactions, mixed reactions (type I/cytokine-release), and delayedtype IV reactions (Isabwe et al., 2018) (Table 1). This new classification encompasses the classic HSRs described by Gell and Coombs as well as reactions outside the classification, but it has no space for type II or III reactions since this classification focuses on the reactions that might benefit from desensitization.

\section{Infusion-Related Reactions}

Patients mostly suffer from common acute infusion reactions that occur in a short time after infusion. Although the pathogenesis of these reactions is not very clear, it's usually affected by the rate of infusion, pointing out to the possibility of a non-immunologic mechanism and the role of the inflammatory

TABLE 1 | Classifications of hypersensitivity reactions to biological agents including rituximab.

\begin{tabular}{|c|c|c|}
\hline $\begin{array}{l}\text { Type of } \\
\text { reaction }\end{array}$ & Mechanism/Diagnostic criteria & References $\mathrm{No} \neq$ \\
\hline $\begin{array}{l}\text { Infusion- } \\
\text { related } \\
\text { reaction }\end{array}$ & $\begin{array}{l}\text { Non-immunologic, monocytes, macrophages, cytotoxic T cells, natural killer cells activation/clinical } \\
\text { presentations and course, levels of IL-1, IL-6, and TNF- } \alpha\end{array}$ & $\begin{array}{l}\text { Pichler, 2006; Corominas et al., 2014; Galvão } \\
\text { and Castells, 2015; Khan, 2016; Isabwe et al., } \\
2018\end{array}$ \\
\hline $\begin{array}{l}\text { Cytokine } \\
\text { release } \\
\text { reaction }\end{array}$ & $\begin{array}{l}\text { Non-immunologic, monocytes, macrophages, cytotoxic T cells, natural killer cells activation/clinical } \\
\text { presentations and course, levels of IL-1, IL-6. and TNF- } \alpha\end{array}$ & $\begin{array}{l}\text { Pichler, 2006; Corominas et al., 2014; Galvão } \\
\text { and Castells, 2015; Khan, 2016; Isabwe et al., } \\
2018\end{array}$ \\
\hline $\begin{array}{l}\text { Type I } \\
\text { reaction (lgE/ } \\
\text { non-lgE) }\end{array}$ & $\begin{array}{l}\text { IgE or non- IgE dependent mast cell, basophil activation/clinical presentations, level of tryptase, skin } \\
\text { tests, BAT }\end{array}$ & $\begin{array}{l}\text { Pichler, 2006; Corominas et al., 2014; Galvão } \\
\text { and Castells, 2015; Khan, 2016; Isabwe et al., } \\
2018\end{array}$ \\
\hline $\begin{array}{l}\text { Mixed } \\
\text { reaction }\end{array}$ & $\begin{array}{l}\text { IgE or non-lgE dependent mast cell, basophil activation and monocytes, macrophages, cytotoxic } T \\
\text { cells, natural killer cells activation/clinical presentations, skin tests, BAT, levels of tryptase, IL-1, IL- } 6 \text {, } \\
\text { and TNF- } \alpha\end{array}$ & $\begin{array}{l}\text { Pichler, 2006; Corominas et al., 2014; Galvão } \\
\text { and Castells, 2015; Khan, 2016; Isabwe et al., } \\
2018\end{array}$ \\
\hline $\begin{array}{l}\text { Type III } \\
\text { reaction }\end{array}$ & $\begin{array}{l}\text { Not clear, may be related to C-fixing IgM and IgG antibodies and Fc-lgG receptor-mediated neutrophil } \\
\text { activation clinical presentations, RF, immunoglobulins, and HACA levels }\end{array}$ & Karmacharya et al., 2015 \\
\hline $\begin{array}{l}\text { Type IV } \\
\text { reaction }\end{array}$ & T-cell mediated or other mechanisms/clinical presentations, immunohistological examination & $\begin{array}{l}\text { Henning and Firoz, 2011; Macdonald et al., } \\
\text { 2015; Fallon and Heck, 2015; Chen et al., } 2018\end{array}$ \\
\hline
\end{tabular}

C, complement; HACA, human anti-chimeric antibody; TNF- $\alpha$, tumor necrosis factor- $\alpha$. 
cytokines such as IL- 6 and tumor necrosis factor- $\alpha$ (Khan, 2016; Patel and Khan, 2017). Clinical presentations resemble type I or cytokine-release, but they are mild to moderate in severity and subside gradually with the following infusions (Plosker and Figgitt, 2003; Galvão and Castells, 2015).

\section{Cytokine Release Reactions}

The phenotype is defined as fever/chills, nausea, pain, headache, and rigors not responding to premedication/slower infusion rate during the first infusion. Clinical symptoms and signs are usually due to the cytokine release that is characterized by elevated serum TNF- $\alpha$ and IL- 6 levels at the time of the reaction compared with their normal baseline (Isabwe et al., 2018).

\section{Type I Reactions (IgE/Non-lgE)}

The reaction is defined as flushing, pruritus, urticaria, shortness of breath, wheezing, hypotension, and life-threatening anaphylaxis. Reactions are associated with $\operatorname{IgE}$ or non-IgE mediated mast cell/basophil degranulation leading to massive histamine, leukotrienes and prostaglandins release. Skin test positivity and/or specific IgE to rituximab is indicative of both IgE-mediated and mixed reactions (Patel and Khan, 2017; Wong and Long, 2017; Isabwe et al., 2018).

\section{Mixed Reactions}

Mixed reactions are a combination of cytokine release and IgEmediated reactions. Clinical presentations are characterized by wheezing, flushing, urticaria, pruritus, with fever/chills, nausea, pain, headache, and rigor. Skin test positivity and/or specific IgE to rituximab as well as increased levels of tryptase, IL-1, IL-6 and TNF- $\alpha$ can occur (Patel and Khan, 2017; Isabwe et al., 2018).

There are limited data on the frequency of HSRs and standard infusion reactions to rituximab. Additionally, the lack of consensus on the definition and classification of HSRs makes the data even confusing (Table 2). Among biological agents, rituximab has the highest reported infusion reactions, with up to $77 \%$ reported with the first infusion (van Vollenhoven et al., 2013). It also has a relatively high rate of HSRs, consistent with the IgE-mediated reactions, reported with 5 to $10 \%$ of infusions (Brennan et al., 2009; Galvão and Castells, 2015). In a study by Isabwe et al., prevalence of type I, cytokine-release, mixed type, and delayed-type IV reactions were reported as $63,13,21$, and $3 \%$ respectively (Isabwe et al., 2018).

Brown classification is commonly used in the classification of severity of HSRs to mAbs. Grade 1 (mild) represents only skin/ subcutaneous involvement, Grade 2 (moderate) presents gastrointestinal, cardiovascular or respiratory system affection, and Grade 3 (severe) consisted of failure of neurologic, respiratory, or cardiovascular systems (Brown, 2004).

\section{Serum Sickness Reactions}

Rituximab-induced serum sickness (RISS, type III) reactions have been observed less commonly. A systematic review reported 33 cases from 25 articles, the majority with underlying rheumatoid diseases. However, the systematic review has limitations such as the lack of confirmatory tests in all cases. Although the pathogenesis is not clear, it seems to be related to complement-fixing IgM and IgG antibodies targeted at an immunogenic part of the drug. The typical presentation has been found in $48.5 \%$ of cases. Symptoms are usually benign and self-limited in mild cases. Corticosteroid treatment may be beneficial, but premedication is not always effective. Correct diagnosis of RISS remains an unmet need (Karmacharya et al., 2015).

\section{Type IV Reactions}

Delayed type IV reactions are mostly presented with a maculopapular rash (Macdonald et al., 2015). Severe cutaneous reactions may occur, but they are probably rare. Two cases of Stevens-Johnson syndrome (SJS), one case of toxic epidermal necrolysis (TEN), and two cases of SJS-TEN caused by rituximab have been reported in a review (Chen et al., 2018). The U.S. FDA adverse events report seven cases of rituximab induced TEN (Fallon and Heck, 2015). There might be a false diagnosis of a case of SJS due to similarities in clinical findings, pathology, and prognosis resembling paraneoplastic pemphigus (PNP). To confirm cases of SJS/TEN in rituximab and differentiate them from PNP, direct and indirect immunofluorescence could be used (Joly et al., 2000; Henning and Firoz, 2011).

\section{DIAGNOSIS}

The detailed clinical history is crucial for determining the type and severity of the HSR (Picard and Galvão, 2017; Yang and Castells, 2019; Görgülü et al., 2019). Different hypersensitivity mechanisms such as type I IgE or non-IgE reactions could give rise to the same clinical picture (Isabwe et al., 2018). In vivo tests such as skin prick test (SPT) and intradermal testing (IDT), drug provocation test (DPT), and in vitro tests including specific IgE, basophil activation test (BAT), serum levels of tryptase, IL-1, IL6 , TNF- $\alpha$, or lymphocyte transformation test (LTT) are used to define the phenotype of the HSR. Clinical history, in vivo and in vitro tests are all essential for personalized and precision medicine, but there is remarkable heterogeneity on diagnostic approaches (Santos and Galvao, 2017; Isabwe et al., 2018; Madrigal-Burgaleta et al., 2020).

\section{Skin Testing as Diagnostic and Predictor for Breakthrough Reactions During Desensitization}

Skin testing is the primary step for assessing HSRs to rituximab (Brennan et al., 2009). Skin test positivity demonstrated through SPT or IDT to rituximab suggests an IgE-mediated reaction. Despite insufficient evidence for optimal timing, skin testing with the culprit drug can be done within 2-4 weeks following the reaction to avoid false negative results (Alvarez-Cuesta et al., 2015; Santos and Galvao, 2017; Isabwe et al., 2018; MadrigalBurgaleta et al., 2020). SPT is done using a drop of concentrated rituximab $10 \mathrm{mg} / \mathrm{ml}$, and if it is negative, IDT is then performed with dilutions from 1:1,000 up to 1:1 (Wong and Long, 2017; Santos and Galvao, 2017; Isabwe et al., 2018). Positivity to rituximab is usually seen with IDT more than SPT. In a study, 
TABLE 2 | Prevalence and severity of HSRs to rituximab.

\begin{tabular}{|c|c|c|}
\hline References & & Types, clinical features, and severity \\
\hline $\begin{array}{l}\text { van Vollenhoven } \\
\text { et al., } 2013 \\
\mathrm{n}=3194 \\
\text { patients }\end{array}$ & -Acute infusion related reactions: $77 \%$ & f patients \\
\hline $\begin{array}{l}\text { Isabwe et al., } \\
2018 \\
n=52 \\
\text { patients }\end{array}$ & Severity & $\begin{array}{l}\text { Acute infusion reactions: } 20-50 \% \\
\text { Type I reactions: } 63 \% \\
\text { Cytokine-release reactions: } 13 \% \\
\text { Mixed reactions: } 21 \% \\
\text { Delayed reactions: } 3 \% \\
\text { Grade I: } 13 \% \text {, Grade II: } 60 \% \text {, Grade III: } 29 \%\end{array}$ \\
\hline
\end{tabular}

$30 \%$ of patients with HSRs to rituximab were positive in IDTs, and none of them were positive in SPT (Görgülü et al., 2019). Similarly, in an early study, IDT for rituximab was positive in six out of nine patients (Brennan et al., 2009). However, in another study, $20 \%$ of the patients were SPT positive, and $32 \%$ were IDT positive among $52 \%$ of skin test positive patients (Isabwe et al., 2018).

Skin test positivity was found to be correlated with the frequency of respiratory symptoms, but not to the severity of the initial reaction to rituximab (Görgülü et al., 2019). However, Isabwe et al. have found that positive rituximab skin testing was strongly associated with severe initial rituximab HSRs. The percentage of type I breakthrough reactions during desensitization was as high as $69 \%$ in patients with a positive skin test. Therefore, skin testing could be helpful in the prediction of the type of breakthrough reactions. On the other hand, breakthrough reactions for skin test negative patients were lower in severity during desensitization (Isabwe et al., 2018). Madrigal-Burgaleta et al. showed that patients with a positive SPT tend to encompass an important percentage of breakthrough reactions during desensitization (Madrigal-Burgaleta et al., 2019). Wong and Long have concluded that there is no significant difference in the risk of a breakthrough reaction if the patient is skin test positive or negative (Wong and Long, 2017). The differences may be due to patient selection, different concentrations and volume used for skin tests, the clinical symptoms of the patients, their severity, the time between the reaction and the study, such differences need to be clarified (Wong and Long, 2017).

\section{Drug Provocation Test}

Data on the use of DPT to biological agents are scarce and come from a few specialized centers. The Ramon y Cajal University
Hospital (RCUH) group is the pioneer of DPT with the largest reported series with antineoplastics and biologicals. They positioned the use of DPT in patients with negative or equivocal skin test results provided the risk-assessment is favorable. There are no international guidelines for DPT with these drugs but the RCUH protocol is based on direct readministration of the culprit drug under standard conditions (Alvarez-Cuesta et al., 2015; Madrigal-Burgaleta et al., 2019; Madrigal-Burgaleta et al., 2020; Martí-Garrido et al., 2020). If patients showed positive skin testing or positive DPT, then the HSR would be confirmed; conversely, a negative DPT would rule out an HSR. Thus, not doing DPTs routinely in the diagnosis of an HSR to biologics could bias the safety or the efficiency of RDD. However, this approach needs trained personnel and wellequipped center that limit its wide implementation (MadrigalBurgaleta et al., 2019).

\section{In Vitro Tests}

In a patient with two immediate reactions to rituximab, nonisotype-specific and sIgE to rituximab were positive in the serum samples. More importantly, rituximab stimulated peripheral blood mononuclear cells displayed a response associated with a Th2 cytokine production profile (Vultaggio et al., 2012). The use of sIgE, BAT, serum levels of tryptase, IL-1, IL-6, TNF- $\alpha$, and LTT as diagnostic tools to biologicals are restricted to selected patients in expert centers (Madrigal-Burgaleta et al., 2020).

\section{MANAGEMENT}

There's a general agreement about avoiding rituximab that has caused type IV HSR such as SJS, TEN, EM and DRESS as well as 
RISS (Hong and Sloane, 2019; Yang and Castells, 2019). For mild to moderate common infusion reactions to rituximab, the manufacturer's instructions are to reduce the rate of infusion and premedicate the patients with an antihistamine, acetaminophen and methylprednisolone prior to dosing and liaise the allergist if required (https://www.ema.europa.eu/en/ documents/product-information/mabthera-epar-productinformation_en.pdf). In the event of an HSR to rituximab such as Type 1, cytokine release, mixed reaction and delayed maculopapular rash, RDD is a safe and valid alternative. The management by multidisciplinary teams led by expert allergists and access to adequate facilities for allergy procedures has shown to be the optimal approach, with the best efficacy and safety results (Isabwe et al., 2018; Görgülü et al., 2019; Hong and Sloane, 2019).

\section{Patient Selection for Rapid Drug Desensitization}

Patients with a clinical history of HSR to biologicals and who have a confirmation from their referring specialist to use the drug as their first line of choice with no better alternatives are possible candidates for RDD (Sloane et al., 2016; Patel and Khan, 2017; Picard and Galvão, 2017). Different groups use different criteria for patient selection for RDD. The Brigham and Women's Hospital (BWH), a very well-known center for RDD, recommends that RDD should always be performed on patients with positive in vivo/in vitro tests, regardless of the grade of the initial HSRs. If the test restults are negative and the initial HSR is Grade I (low risk), a challenge may be performed. If there is no reaction during the challenge, the patient can be sent back to regular infusion. However, if there is a reaction, RDD should be performed for the next drug exposure. If the test results are negative and the initial HSR is Grade II/III (moderate-high risk), RDD is indicated (Castells, 2009; Galvão and Castells, 2015; Isabwe et al., 2018). RCUH considers that DPT should always be performed systematically prior to RDD, but only if the riskassessment for the patient is favorable. This risk-assessment strategy involves a number of factors (e.g. ST, serum biomarkers, patient comorbidities, and patient wishes) and is discussed in a collaborative decision-making process including the referring physician, the allergist, and the patient (who makes the final decision) (Alvarez-Cuesta et al., 2015; MadrigalBurgaleta et al., 2019).

\section{Premedication in Rapid Drug Desensitization}

Premedication is a controversial issue and there is no categorical recommendation. BWH recommends routine pre-medications in all desensitization protocols such as cetirizine $10 \mathrm{mg}$, montelukast $10 \mathrm{mg}$, or zileuton to prevent bronchospasm, famotidine $20 \mathrm{mg}$ for $\mathrm{H} 1$ and $\mathrm{H} 2$ blockage, and aspirin 81 to $325 \mathrm{mg}$ to prevent flushing caused by prostaglandins. As well as ibuprofen 200 to $800 \mathrm{mg}$, meperidine $25 \mathrm{mg}$, or acetaminophen $650 \mathrm{mg}$ for prevention of rigors, pain, and fever. 40 to $50 \mathrm{mg}$ methylprednisolone or other steroids are needed in cases of more severe reactions. Benzodiazepines can be added to control anxiety (Brennan et al., 2009; Castells, 2009; Görgülü et al., 2019; Yang and Castells, 2019).

Contrary, RCUH Allergy Division Desensitization Program showed that in a limited number of patients with confirmed hypersensitivity to Paclitaxel, desensitization alone might be more than enough to control allergic reactions, and premedication with antihistamines and corticosteroids made no difference to the breakthrough reactions (Lopez-Gonzalez et al., 2018). The same group currently reported that they used only standard premedication for each drug (according to prescribing information by the manufacturer and institutional protocols) but for some cases additional premedication customized to their initial or breakthrough reactions (Madrigal-Burgaleta et al., 2019). Their results show no significant increase in the number or severity of breakthrough reactions when compared with results reported by other groups (Brennan et al., 2009; Sloane et al., 2016; Picard and Galvão, 2017; Isabwe et al., 2018).

Even if evidence is weak and the topic is controversial, whenever possible, $\beta$-blockers and ACE-Inhibitors should be avoided one day prior to desensitization as the former blocks the action of epinephrine and the latter may even aggravate immediate reaction (Aberer et al., 2003; Lebel et al., 2016; Görgülü et al., 2019; Madrigal-Burgaleta et al., 2019; Yang and Castells, 2019).

Available data suggest that systematic use of premedication may not play a significant role in improving the effectiveness and safety of RDD and should be carefully and individually discussed if their only purpose is to prevent breakthrough reactions. All groups seem to be recommended a personalized approach and further studies are needed for optimal premedication protocols (Table 4).

\section{Rapid Desensitization Protocols}

Several protocols have been proposed (Puchner et al., 2001; Jerath et al., 2009; Amorós-Reboredo et al., 2015; Madrigal-Burgaleta et al., 2019). However, the protocol developed by the BWH has gained wide acceptance. The 12-step protocol consists of three bags, where tolerance to the offending antigen dose is obtained by giving the patient 2 to 2.5 incremental doses of the drug, through increasing the rate of infusion and the concentration of the drug at fixed 15-min intervals. The remaining amount of the total dose is infused at a steady rate of infusion in the last step. A 4-bag, 16-step protocol can be initiated for more severe reactions (Castells, 2009). Few studies specifically focused on rituximab desensitization (Table 3) (Brennan et al., 2009; Amorós-Reboredo et al., 2015; Ataca et al., 2015; Tal et al., 2016; Wong and Long, 2017; Görgülü et al., 2019). A recent study with $141 \mathrm{RDD}$ in reported that only $14 \mathrm{RDD}$ were interrupted by breakthrough reactions leading to the incompletion of two desensitizations only due to development of anaphylaxis, with a success rate for RDD of $98.5 \%$. Usually, breakthrough reactions are mild and develop in the last steps of the protocol (Görgülü et al., 2019). In another study, five patients have had 19 desensitizations to rituximab where all RDDs were successful. Only two patients have 
TABLE 3 | Rapid desensitization protocols data from different studies.

\begin{tabular}{|c|c|c|c|c|}
\hline Reference & $\begin{array}{c}\text { Patients/Desensitization } \\
\text { number }\end{array}$ & RDD protocol Success rate & BTRs & $\begin{array}{l}\text { Skin test } \\
\text { positivity }\end{array}$ \\
\hline Brennan et al., 2009 & $14 / 55$ & $\begin{array}{l}\text { 12-step protocol } \\
100 \% \text { successful }\end{array}$ & $\begin{array}{l}40 \% \text { of patients Grade } 1 \\
\text { reaction }\end{array}$ & IDT: 6/9 patients \\
\hline $\begin{array}{l}\text { Amorós-Reboredo et al., } \\
2015\end{array}$ & $5 / 19$ & $\begin{array}{l}\text { 12-step protocol } \\
100 \% \text { successful }\end{array}$ & $\begin{array}{l}2 \text { patients } \\
\text { had neuromuscular reactions }\end{array}$ & IDT: $2 / 5$ patients \\
\hline Tal et al., 2016 & $7 / 53$ & $\begin{array}{l}\text { Modified 12-step protocol } \\
\text { 100\% successful }\end{array}$ & Grade 1 reaction in 3 RDDs & ND \\
\hline Görgülü et al., 2019 & $24 / 141$ & $\begin{array}{l}\text { 12-step protocol } \\
16 \text {-step in patients with severe reactions } \\
98.5 \% \text { successful }\end{array}$ & $\begin{array}{l}14 \text { patients } \\
\text {-Grade 1: } 17 \% \\
\text {-Grade 2: 33\% } \\
\text {-Grade 3: } 8 \% \\
\text {-2 RDDs couldn't be } \\
\text { completed }\end{array}$ & $\begin{array}{l}\text { IDT: 6/ } \\
\text { 20patients }\end{array}$ \\
\hline
\end{tabular}

BTRs, Break Through Reactions; NP, No data; IDT, Intradermal test.

*Data was not provided specifically on the rituximab-reactive patients but extracted from biological patients as a whole.

TABLE 4 | Unmet needs and future research for HSRs to rituximab.

\begin{tabular}{|c|c|}
\hline Classification & $\begin{array}{l}\text { Clear and acceptable classification for the type of reaction } \\
\text { Well defined criteria for this classification } \\
\text { Clear clinical and laboratory criteria to differentiate the type of } \\
\text { reactions } \\
\text { Effective biomarkers for clear endotyping underlying reactions }\end{array}$ \\
\hline Epidemiology & $\begin{array}{l}\text { Lack of data about morbidity and mortality of each type } \\
\text { of reactions }\end{array}$ \\
\hline RISS* & $\begin{array}{l}\text { Clinical trials in such patients with allergist involvement to } \\
\text { obtain better evidence for the diagnostic criteria and } \\
\text { management }\end{array}$ \\
\hline SCARs ${ }^{* *}$ & $\begin{array}{l}\text { Clearly understanding the mechanism and diagnostic } \\
\text { methods } \\
\text { The differential diagnosis in case of exposure to other } \\
\text { concomitant medications that are known to cause SCARs }\end{array}$ \\
\hline Skin tests & $\begin{array}{l}\text { Non-irritant dose of rituximab } \\
\text { The high cost of rituximab to use for skin tests } \\
\text { Lack of skin test reagents containing all the immune epitopes } \\
\text { Perfect timing for doing skin tests after an HSR } \\
\text { Role of skin test in the prediction of breakthrough reactions } \\
\text { The role of patch test in the diagnosis of delayed-type reaction }\end{array}$ \\
\hline In vitro tests & Their roles in diagnosis \\
\hline Desensitization & $\begin{array}{l}\text { Optimal premedication protocols } \\
\text { Candidates for desensitization }\end{array}$ \\
\hline $\begin{array}{l}\text { Cross- } \\
\text { reactivity }\end{array}$ & $\begin{array}{l}\text { Between rituximab, obinutuzumab, ofatumumab, veltuzumab } \\
\text { and ocrelizumab }\end{array}$ \\
\hline OVERALL & $\begin{array}{l}\text { A multidisciplinary team study including allergists, } \\
\text { pharmacologists, nurses, oncologists, hematologists, and } \\
\text { other specialties to improve the diagnostic approach and } \\
\text { management of HSR s to mAbs and to overcome the } \\
\text { unmet needs }\end{array}$ \\
\hline
\end{tabular}

${ }^{*}$ Rituximab induced serum sickness, ${ }^{*}$ Severe cutaneous adverse reaction. developed breakthrough reactions in the form of neuromuscular reactions. Two out of five patients had positive IDT (AmorósReboredo et al., 2015). Wong and Long have demonstrated that out of 25 patients, $29 \%$ have experienced breakthrough reactions. IDTs only were positive in five of 18 patients. All 170 RDDs were conducted successfully using high-risk, intermediate or rapid protocols that consisted of 3-8 steps (Wong and Long, 2017). Brennan and colleagues have successfuly completed all 55 RDDs to rituximab for 14 patients with a 12 -step protocol, where $40 \%$ of patients had symptoms of grade 1 breakthrough reactions. Only nine patients underwent IDT showing six positive results (Brennan et al., 2009). A different study has performed 53 RDDs on seven patients without skin testing. They used a modified 12-step protocol with $100 \%$ success. Grade 1 breakthrough reactions were reported in three RDDs (Tal et al., 2016).

\section{Management of Breakthrough Reactions During Desensitization}

The rapid desensitization protocol does not need to be suspended because of a breakthrough reaction. Once the reaction is controlled, the RDD protocol can be reinitiated and followed to completion.

Breakthrough reactions to rituximab were generally mild. However, moderate and severe reactions may appear, although less frequently than mild reactions, and the majority of desensitizations were completed (Lebel et al., 2016; Görgülü et al., 2019). Cutaneous involvement has been the main feature of breakthrough reactions (Brennan et al., 2009; Görgülü et al., 2019). If a breakthrough reaction occurs, the infusion must be immediately stopped, and specific medications should be given according to the symptoms experienced. For future RDD, protocols should be customized based on the severity, 
symptoms and type of breakthrough reaction such as additional premedication and/or dilutions (Madrigal-Burgaleta et al., 2019; Yang and Castells, 2019).

\section{CONCLUSION}

Although rituximab is generally well tolerated, its widespread use has entailed an increase in the number of HSRs. There are different proposed classifications for HSRs to mAbs including rituximab with some degree of overlap. Each type of HSR has its features, course, and management. The new proposed classification seems to have clinical implication in terms of a personalized and precise approach. Skin tests, done 2-4 weeks after reaction, is the first step in the diagnostic algorithm and in case of negativity, should be followed by DPT in the availability of adequate settings. RDD is considered a cornerstone of treatment for patients with immediate-type HSRs to rituximab, whereas it seems to be performed in few centers. Therefore, desensitization approach needs more awareness and needs to gain more acceptance. Overall, institutional multidisciplinary teams promoted by allergists to manage HSRs to mAbs including rituximab is crucial.

\section{REFERENCES}

https://www.ema.europa.eu/en/documents/product-information/mabthera-eparproduct- information_en.pdf.

Aberer, W., Bircher, A., Romano, A., Blanca, P., Campi, J., Fernandez, K., et al. (2003). Drug provocation testing in the diagnosis of drug hypersensitivity reactions: general considerations. Allergy 58 (9), 854-863. doi: 10.1034/j.13989995.2003.00279.x

Alvarez-Cuesta, E., Madrigal-Burgaleta, R., Angel-Pereira, D., Ureña-Tavera, A., Zamora-Verduga, M., Lopez-Gonzalez, P., et al. (2015). Delving into cornerstones of hypersensitivity to antineoplastic and biological agents:value of diagnostic tools prior to desensitization. Allergy 70 (7), 784-794. doi: 10.1111/all.12620

Amorós-Reboredo, P., Sánchez-López, J., Bastida-Fernández, C., do Pazo-Oubiña, F., Borràs-Maixenchs, N., Giné, E., et al. (2015). Desensitization to rituximab in a multidisciplinary setting. Int. J. Clin. Pharm. 37 (5), 744-748. doi: 10.1007/ s11096-015-0136-x

Ataca, P., Atilla, E., Kendir, R., Bavbek, S., and Ozcan, M. (2015). Successful Desensitization of a Patient with Rituximab Hypersensitivity. Case Rep. Immunol. 2015, 1-4. doi: 10.1155/2015/524507

Beck, A., Wurch, T., Bailly, C., and Corvaia, N. (2010). Strategies and challenges for the next generation of therapeutic antibodies. Nat. Rev. Immunol. 10 (5), 345-352. doi: 10.1038/nri2747

Brennan, P. J., Bouza, T. R., Hsu, F. I., Sloane, D. E., and Castells, M. C. (2009). Hypersensitivity reactions to mAbs: 105 desensitizations in 23 patients, from evaluation to treatment. J. Allergy Clin. Immunol. 124 (6), 1259-1266. doi: 10.1016/j.jaci.2009.09.009

Brown, S. G. A. (2004). Clinical features and severity grading of anaphylaxis. J. Allergy Clin. Immunol. Aug114 (2), 371-376. doi: 10.1016/j.jaci.2004.04.029

Castells, M. (2009). Rapid Desensitization for Hypersensitivity Reactions to Medications. Immunol. Allergy Clin. North Am. Aug29 (3), 585-606. doi: 10.1016/j.iac.2009.04.012

Chen, C.-B., Wu, M.-Y., Ng, C. Y., Lu, C.-W., Wu, J., Kao, P.-H., et al. (2018). Severe cutaneous adverse reactions induced by targeted anticancer therapies and immunotherapies. Cancer Manag. Res. 10, 1259-1273. doi: 10.2147/ CMAR.S163391

\section{PERSPECTIVES}

New mAbs targeting CD20, obinutuzumab, ofatumumab, veltuzumab and ocrelizumab have been currently introduced to the market. Infusion reactions are the most common adverse event reported with these anti-CD20 mAbs, whether chimeric, humanized or human. However, the relative frequencies have not been studied in a head-to-head fashion. There is no data about cross-reactivity between these mAbs. This may be related to the exclusion of patients with a history of severe allergic reactions to these mAbs from such studies (Gelfand et al., 2017; Salles et al., 2017) (Table 4).

\section{UNMET NEEDS AND FUTURE RESEARCH}

There are several unmet needs (Table 4) that will lead to future research in this area.

\section{AUTHOR CONTRIBUTIONS}

SB directed the writing and was responsible for the overall guidance. GF and SB wrote and revised the manuscript.

Corominas, M., Gastaminza, G., and Lobera, T. (2014). Hypersensitivity Reactions to Biological Drugs. J. Invest. Allergol. Clin. Immunol. 24, 14.

Fallon, M. J., and Heck, J. N. (2015). Fatal Stevens-Johnson syndrome/toxic epidermal necrolysis induced by allopurinol-rituximab-bendamustine therapy. J. Oncol. Pharm. Pract. 21 (5), 388-392. doi: 10.1177/ 1078155214533368

Galvão, V. R., and Castells, M. C. (2015). Hypersensitivity to Biological AgentsUpdated Diagnosis, Management, and Treatment. J. Allergy Clin. Immunol. Pract. 3 (2), 175-185. doi: 10.1016/j.jaip.2014.12.006

Gelfand, J. M., Cree, B. A. C., and Hauser, S. L. (2017). Ocrelizumab and Other CD20 ${ }^{+}$B-Cell-Depleting Therapies in Multiple Sclerosis. Neurotherapeutics 14 (4), 835-841. doi: 10.1007/s13311-017-0557-4

Görgülü, B., Seval, G., Kendirlinan, R., Toprak, S., Özcan, M., and Bavbek, S. (2019). Rapid Drug Desensitization With Rituximab in 24 Cases: A SingleCenter Experience. J. Invest. Allergol. Clin. Immunol. 29 (6), 468-470. doi: 10.18176/jiaci.0445

Henning, J. S., and Firoz, B. F. (2011). Rituxan is not associated with StevensJohnson Syndrome. Ann. Oncol. 22 (6), 1463-1464. doi: 10.1093/annond mdr254

Hong, D., and Sloane, D. E. (2019). Hypersensitivity to monoclonal antibodies used for cancer and inflammatory or connective tissue diseases. Ann. Allergy Asthma Immunol. 123 (1), 35-41. doi: 10.1016/j.anai.2019.04.015

Isabwe, G. A. C., Garcia Neuer, M., de las Vecillas Sanchez, L., Lynch, D.-M., Marquis, K., and Castells, M. (2018). Hypersensitivity reactions to therapeutic monoclonal antibodies: Phenotypes and endotypes. J. Allergy Clin. Immunol. 142 (1), 159-170.e2. doi: 10.1016/j.jaci.2018.02.018

Jerath, M. R., Kwan, M., Kannarkat, M., Mirakhur, B., Carey, L., Valgus, J., et al. (2009). A desensitization protocol for the mAb cetuximab. J. Allergy Clin. Immunol. 123 (1), 260-262. doi: 10.1016/j.jaci.2008.09.046

Joly, P., Richard, C., Gilbert, D., Courville, P., Chosidow, O., Roujeau, J. C., et al. (2000). Sensitivity and specificity of clinical, histologic, and immunologic features in the diagnosis of paraneoplastic pemphigus. J. Am. Acad. Dermatol. 43 (4), 619-626. doi: 10.1067/mjd.2000.107488

Karmacharya, P., Poudel, D. R., Pathak, R., Donato, A. A., Ghimire, S., Giri, S., et al. (2015). Rituximab-induced serum sickness: A systematic review. Semin. Arthritis Rheum. 45 (3), 334-340. doi: 10.1016/j.semarthrit.2015.06.014 
Khan, D. A. (2016). Hypersensitivity and immunologic reactions to biologics: opportunities for the allergist. Ann. Allergy Asthma Immunol. 117 (2), 115120. doi: $10.1016 /$ j.anai.2016.05.013

Lebel, E., Ben-Yehuda, D., Bohbot, E., Dranitzki, Z., Shalit, M., and Tal, Y. (2016). Hypersensitivity reactions to rituximab: 53 successful desensitizations in 7 patients with severe, near-fatal reactions. J. Allergy Clin. Immunol. Pract. 4 (5), 1000-1002. doi: 10.1016/j.jaip.2016.05.013

Levin, A., Otani, I., Lax, T., Hochberg, E., and Banerji, A. (2017). Reactions to Rituximab in an Outpatient Infusion Center: A 5-Year Review. J. Allergy Clin. Immunol: Pract. 5 (1), 107-113.e1. doi: 10.1016/j.jaip.2016.06.022

Li, G. N., Wang, S. P., Xue, X., Qu, X. J., and Liu, H. P. (2013). Monoclonal antibody-related drugs for cancer therapy. Drug Discovery Ther. 7 (5), 178-184. doi: 10.5582/ddt.2013.v7.5.178

Lopez-Gonzalez, P., Madrigal-Burgaleta, R., Carpio-Escalona, L. V., Bernal-Rubio, L., Guerra, E., Berges-Gimeno, M. P., et al. (2018). Assessment of Antihistamines and Corticosteroids as Premedication in Rapid Drug Desensitization to Paclitaxel: Outcomes in 155 Procedures. J. Allergy Clin. Immunol. Pract. 6 (4), 1356-1362. doi: 10.1016/j.jaip.2017.11.013

Macdonald, J. B., Macdonald, B., Golitz, L. E., LoRusso, P., and Sekulic, A. (2015). Cutaneous adverse effects of targeted therapies: Part I: Inhibitors of the cellular membrane. J. Am. Acad. Dermatol. 72 (2), 203-218. doi: 10.1016/j.jaad. 2014.07.032

Madrigal-Burgaleta, R., Bernal-Rubio, L., Berges-Gimeno, M. P., Carpio-Escalona, L. V., Gehlhaar, P., and Alvarez-Cuesta, E. (2019). A Large Single-Hospital Experience Using Drug Provocation Testing and Rapid Drug Desensitization in Hypersensitivity to Antineoplastic and Biological Agents. J. Allergy Clin. Immunol. Pract. 7 (2), 618-632. doi: 10.1016/j.jaip.2018.07.031

Madrigal-Burgaleta, R., Vazquez-Revuelta, P., Marti-Garrido, J., Lleonart, R., Ali, F. R., and Alvarez-Cuesta, E. (2020). Importance of Diagnostics Prior to Desensitization in New Drug Hypersensitivity: Chemotherapeutics and Biologicals. Curr. Treat Options Allergy 7, 1-13. doi: 10.1007/s40521-020-00238-y

Makatsori, M., Kiani-Alikhan, S., Manson, A. L., Verma, N., Leandro, M., Gurugama, N. P., et al. (2014). Hypogammaglobulinaemia after rituximab treatment-incidence and outcomes. QJM 107 (10), 821-828. doi: 10.1093/ qjmed/hcu094

Martí-Garrido, J., Vázquez-Revuelta, P., Lleonart-Bellfill, R., Molina-Mata, K., Muñoz-Sánchez, C., and Madrigal-Burgaleta, R. (2020). Pilot experience using drug provocation testing for the study of hypersensitivity to chemotherapy and biological agents [published online ahead of print, 2020 Jun 23]. J. Invest. Allergol. Clin. Immunol. 31 (1). doi: 10.18176/jiaci.0552

Özyiğit, L. P., Öztürk, A. B., and Bavbek, S. (2020). Anti-IL-5 Biologicals Targeting Severe Late Onset Eosinophilic Asthma. Turk. Thorac. J. 21 (1), 61-68. doi: 10.5152/TurkThoracJ.2019.180204

Patel, S. V., and Khan, D. A. (2017). Adverse Reactions to Biologic Therapy. Immunol. Allergy Clin. North Am. 37 (2), 397-412. doi: 10.1016/j.iac.2017.01.012

Picard, M., and Galvão, V. R. (2017). Current Knowledge and Management of Hypersensitivity Reactions to Monoclonal Antibodies. J. Allergy Clin. Immunol. Pract. 5 (3), 600-609. doi: 10.1016/j.jaip.2016.12.001

Pichler, W. J. (2006). Adverse side-effects to biological agents. Allergy 61 (8), 912920. doi: 10.1111/j.1398-9995.2006.01058.x

Plosker, G. L., and Figgitt, D. P. (2003). Rituximab: a review of its use in nonHodgkin's lymphoma and chronic lymphocytic leukaemia. Drugs 63 (8), 803843. doi: $10.2165 / 00003495-200363080-00005$
Puchner, T. C., Kugathasan, S., Kelly, K. J., and Binion, D. G. (2001). Successful desensitization and therapeutic use of infliximab in adult and pediatric Crohn's disease patients with prior anaphylactic reaction. Inflammation Bowel Dis. 7 (1), 34-37. doi: 10.1097/00054725-200102000-00005

Salles, G., Barrett, M., Foà, R., Maurer, J., O’Brien, S., Valente, N., et al. (2017). Rituximab in B-Cell Hematologic Malignancies: A Review of 20 Years of Clinical Experience. Adv. Ther. 34 (10), 2232-2273. doi: 10.1007/s12325-017-0612-x

Santos, B. R., and Galvao, V. R. (2017). Monoclonal antibodies hypersensitivity. Prevalence and management. Immunol. Allergy Clin. N. Am. 37, 695-711. doi: 10.1016/j.iac.2017.07.003

Sloane, D., Govindarajulu, U., Harrow-Mortelliti, J., Barry, W., Hsu, F. I., Hong, D., et al. (2016). Safety, Costs, and Efficacy of Rapid Drug Desensitizations to Chemotherapy and Monoclonal Antibodies. J. Allergy Clin. Immunol. Pract. 4 (3), 497-504. doi: 10.1016/j.jaip.2015.12.019

Tal, Y., Ben Yehuda, D., Shalit, M., and Lebel, E. (2016). Hypersensitivity Reactions to Rituximab: 53 Successful Desensitizations in 7 Patients with Severe, Near-Fatal Reactions. J. Allergy Clin. Immunol. 137 (2), AB39. doi: 10.1016/j.jaci.2015.12.131

van Vollenhoven, R. F., Emery, P., Bingham, C. O., Keystone, E. C., Fleischmann, R. M., Furst, D. E., et al. (2013). Long-term safety of rituximab in rheumatoid arthritis: 9.5-year follow-up of the global clinical trial programme with a focus on adverse events of interest in RA patients. Ann. Rheum. Dis. 72 (9), 14961502. doi: 10.1136/annrheumdis-2012-201956

Vidal, L., Gafter-Gvili, A., Salles, G., Dreyling, M. H., Ghielmini, M., Hsu Schmitz, S.-F., et al. (2011). Rituximab maintenance for the treatment of patients with follicular lymphoma: an updated systematic review and meta-analysis of randomized trials. J. Natl. Cancer Inst. 103 (23), 1799-1806. doi: 10.1093/ jnci/djr418

Vikse, J., Jonsdottir, K., Kvaløy, J. T., Wildhagen, K., and Omdal, R. (2019). Tolerability and safety of long-term rituximab treatment in systemic inflammatory and autoimmune diseases. Rheumatol. Int. 39 (6), 1083-1090. doi: 10.1007/s00296-019-04272-1

Vultaggio, A., Matucci, A., Nencini, F., Pratesi, S., Petroni, G., Cammelli, D., et al. (2012). Drug-specific Th2 cells and IgE antibodies in a patient with anaphylaxis to rituximab. Int. Arch. Allergy Immunol. 159 (3), 321-326. doi: 10.1159/ 000336839

Wong, J. T., and Long, A. (2017). Rituximab Hypersensitivity: Evaluation, Desensitization, and Potential Mechanisms. J. Allergy Clin. Immunol. Pract. 5 (6), 1564-1571. doi: 10.1016/j.jaip.2017.08.004

Yang, B. C., and Castells, M. C. (2019). Rituximab hypersensitivity and desensitization. Ann. Allergy Asthma Immunol. 123 (1), 11-15. doi: 10.1016/ j.anai.2019.03.008

Conflict of Interest: The authors declare that the research was conducted in the absence of any commercial or financial relationships that could be construed as a potential conflict of interest.

Copyright $\odot 2020$ Fouda and Bavbek. This is an open-access article distributed under the terms of the Creative Commons Attribution License (CC BY). The use, distribution or reproduction in other forums is permitted, provided the original author $(s)$ and the copyright owner(s) are credited and that the original publication in this journal is cited, in accordance with accepted academic practice. No use, distribution or reproduction is permitted which does not comply with these terms. 